\title{
Attitudes towards English in Ghana
}

\author{
Kari Dako \\ Associate Professor, Department of English, \\ University of Ghana, Legon, Ghana \\ karidako@ug.edu.gh; karidako@gmail.com \\ Millicent Akosua Quarcoo \\ Senior Lecturer, Department of English Education, \\ University of Education, Winneba, Ghana \\ maquarcoo@uew.edu.gh; akosquarcoo@gmail.com
}

Submitted: May 16, 2014 /Accepted: September 4, 2014 / Published: May 31, 2017

\begin{abstract}
The paper considers official and individual attitudes towards bilingualism in English and a Ghanaian language. We ask whether bilingualism in English and Ghanaian languages is a social handicap, without merit, or an important indicator of ethnic identity. Ghana has about 50 non-mutually intelligible languages, yet there are no statistics on who speaks what language(s) where in the country. We consider attitudes to English against the current Ghanaian language policy in education as practised in the school system. Our data reveal that parents believe early exposure to English enhances academic performance; English is therefore becoming the language of the home.
\end{abstract}

Keywords: attitudes, English, ethnicity, Ghanaian languages, language policy

\section{Introduction}

Asanturofie anomaa, wofa no a, woafa mmusuo, wogyae no a, wagyae siadeé.

(If you catch the beautiful nightjar, you inflict on yourself a curse, but if you let it go, you have lost something of great value).

The attitude of Ghanaians to English is echoed in the paradox of this well-known Akan proverb. English might be a curse but it is at the same time a valuable necessity. Attitudes are learned, and Garret (2010) reminds us that associated with attitudes are 'habits, values, beliefs, opinions as well as social stereotypes and ideologies' (p.31). In order to get the type of data we sought, a direct approach was used to elicit information about attitudes to English, English medium education, preferred language in the work place, in commerce and in the media.

Ghana, as a former British colony, is among the 'Anglophone' countries of Africa. Even though Ghana has about '50 non-mutually intelligible languages"' (Anyidoho \& Kropp-Dakubu, 2008, p.142), English is the official language, and at the same time also the most prestigious language (Guerini, 2008). Competence in English is highly regarded (Sey, 1973; Saah, 1986; Andoh-Kumi, 1997) and all evidence suggests that fluency in English is both admired and respected. English is the key to social mobility in Ghana, and throughout the education system, a pass in English is a necessity in propelling one to the next level of the educational ladder. As a result, English is encroaching on some domains previously reserved for local languages. In a second-language situation, the official language will always put the local languages at a disadvantage for it is only through the official language that access to official documents such as, for instance, the constitution and educational opportunities is possible. English is also socially diagnostic in that it appears to suggest that speakers of English belong to a desirable class, or are engaged in sought-after activities in society and thus 'creating a language-based 
system of social stratification that favours a small, educated African elite' (McLaughlin, 2009, p.3) ${ }^{1}$.

\section{English in Ghana}

According to a 2007 estimate made by the United Nations, only about $31.8 \%$ of Ghana's population can be said to have English proficiency. So we agree with Mufwene (2010, p.59) when he raises the question: 'Who counts as Anglophone?' And when he further probes what 'demographic or ethnographic criteria' and 'what proportion of its population, with what level of competence' a country should have in order to consider itself Anglophone, i.e. be considered an English-speaking country.

At present British Standard English (BSE) is the written target language of education, and from Primary Four it is, or is supposed to be, the language of instruction in all subjects, except the subject: Ghanaian Language. Received Pronunciation (RP) is the examinable spoken norm and thus the target in spoken English. But whereas Ghana has examiners that are competent to examine BSE, Ghana is short of competent examiners of RP in spoken discourse. On the other hand, information from both high schools and colleges of education suggests that Oral English is no longer part of the syllabus. Although a British accent has always been the official target, it is not popular among Ghanaians. Dako (1991) and surveys among students at the University of Ghana over the years show that Ghanaian English (GhE) is initially conceptualised as an accent, and that Ghanaians are comfortable with and identify with their mode of speech. Koranteng (2006, p.23) describes the situation as: 'an interesting state of affairs ... the educated Ghanaian thinks he speaks British Standard English, and yet frowns on any type of pronunciation that approximates RP'. There is, however, some disagreement on what constitutes the "educated" Ghanaian accent, and who should be thought the ideal speaker. (Dako, 2003; Adjaye, 2005; Koranteng, 2006; Huber, 2008).

On the other hand, an American accent appears to be both acceptable and popular among younger speakers. This is especially noticeable on the numerous local FM stations where we hear young announcers speaking with an attempted American accent. This phenomenon is locally referred to with the acronym: LAFA, which stands for 'locally acquired foreign accent' (Huber, 2008; Bruku, 2010; Arthur-Shoba, Dako \& Quartey, 2012).

Ghanaian English (GhE) is a new variety, one of the New Englishes (Platt, Weber \& Ho, 1984; Bamgbose, 1995) in the process of nativisation (Schneider 2003) and is identified through phonological features, lexis, pragmatic peculiarities and idiomatic usage. Structurally, there are tendencies that mark GhE as distinct from BSE (Huber \& Dako, 2008), but these are tendencies mostly identifiable in terms of frequency and along the performance cline. There is the debate whether some persistent features of usage should be accepted as local variety markers or discouraged as grammatical mistakes (deviant structures). Many Ghanaians consider English a Ghanaian language that should set its own norms. A distinct concept of acceptable local usage is therefore evolving. Whereas BSE, as an exolanguage (alien language), is formally the written norm, an indigenised $\mathrm{GhE}$ is the written and spoken code in non-formal intra-national discourse. GhE has not assumed an endonormative status (Anderson, 2009) (i.e. assuming local forms). The spoken language carries more local markers than the written, but whereas evidence from Dako (1991) reveals that educated Ghanaians claim that local lexical variety markers are used exclusively in spoken discourse, Dako (2003b) shows that local lexical variety markers are recurrent in almost all genres of written discourse.

\section{The Ghanaian English Speaker}

Most Ghanaian English speakers are bilingual with at least one local language in addition to English. We also reckon that more than $70 \%$ of Ghanaians can speak an Akan dialect (Twi, Fante, etc.)If we say that most Ghanaian English speakers are bilingual, yet find in our surveys that most urban middle class parents interviewed appear indifferent to ensuring that their children get access to a local language and are thus encouraging monolingualism in their children, how do these parents view their own bilingualism? What is the relationship between identity, attitude to English and attitude to

See also Chimbutane (2011). 


\section{Dako \& Quarcoo / Legon Journal of the Humanities (2017) 20-30}

the mother tongue ${ }^{2}$ (L1)? Is speaking English and a local language in Ghana viewed as a social handicap, as without merit, or as an important indicator of a person's ethnic identity?

We have over the years asked students at the University of Ghana whether they consider their bilingualism an asset. The responses have invariably been that their bilingualism is not a social handicap, but that bilingualism in English and a local language(s) might be considered without merit, as the knowledge of a local language hardly ever has any economic value. This perception is clearly demonstrated in class when students are introduced to strategies on how to write a Curriculum Vitae. Students do not consider the item: 'languages spoken' - and if they do, they invariably list: 'English/ French/ Spanish/ Russian' etc. but not any Ghanaian languages. On the other hand, the Ghanaian L1 is by most students considered an important indicator of ethnic identity.

\section{Official Attitudes to English in Education}

For Baker and Prys-Jones (1998, p. 178), 'any policy for language, especially in the system of education, has to take account of the attitudes to those likely to be affected.' And as Tollefson (1991, p. 6) as quoted in Chimbutane (2012, p.15) emphasises, 'language policy is one mechanism for locating language within social structure so that language determines who has access to political power and economic resources'.

It is not clear what general language policy prevails in Ghana today, and officialdom has never systematically sought information on who speaks what where in Ghana. The present language policy in education appears to accommodate the attitudes of the urban middle class: that the child is best catered for in an English medium school. Whether the attitudes of non-English-speaking parents of rural as well as urban children have been taken cognisance of in any language policy is unclear. When a former Minister for Education in the New Patriotic Party (NPP) administration introduced an English-only policy in 2002, he gave some reasons for his decision, and one of these was that 'students are unable to speak and write good[emphasis added] English sentences even by the time they complete the senior secondary school' (TheStatesman 2002, p. 3.). In addition he argued that English was the lingua franca of the State and that everything must be done to ensure that children acquire the right level of competence in both the spoken and written forms of the language. The minister did not consider whether there were competent teachers available to teach English from kindergarten.

In 2006, therefore, four years later, Ghana introduced yet another policy on language in education - the National Literacy Accelerated Programme (NALAP). According to NALAP, the child will be taught in its L1, or the dominant language of the locality, for the first three years of primary school while being introduced to English gradually first in speech and later in writing. From the fourth year, English is the sole medium of instruction, and the local language is taught as a subject. The Ghanaian language of the community will be offered as a compulsory subject to BECE (Basic Education Certificate Examination). Exception to this policy is granted to a select few schools in urban areas that have a large number of expatriate children, such as Ghana International School and École Française Jacques Prévert. Other English medium schools now have to offer a Ghanaian language as a subject, but they do not feel obliged to teach in a Ghanaian language for the first three years. On the other hand, a Ghanaian language is now one of the ten compulsory subjects at BECE. The pupil must pass in all the ten subjects, but only six subjects constitute the aggregate necessary for admission into a Senior High School, and 'Ghanaian Language' is not one of these six subjects.

As a consequence of this language policy, very few Senior High Schools offer a local language. Pupils have tended not to take their Ghanaian language lessons seriously, because a pass in the subject cannot help them to advance academically. This attitude has then also been supported from the home in that parents encourage their children to concentrate on 'important subjects' i.e. subjects that count towards the admittance aggregate for high school and university. Consequently, young people come out of school unable to read or write any of the indigenous languages, because no premium is put on this competence.

Till a couple of years ago, therefore, the educational philosophy as practised in private urban

2 Also first language 
schools and by middle class parents in urban Ghana is what García (2007, p. 51) calls 'subtractive bilingualism' in that the child 'speaks a first language and a second is added while the first is subtracted'. What this means is that the dominant language, which in Ghana's case is English, will ease out the $\mathrm{L} 1$ and replace it.

\section{General Attitudes to English}

Ghanaians are proud of their competence in English and, as mentioned above, competence in English is highly regarded. Students in the Department of English, University of Ghana, interviewed over the years have been close to unanimous in the view that the Ghanaian speaks better English than any other English-speaking African. The reference points for most of the students are restricted to Nigerian English and Liberian English. But the same view tends to be expressed by Ghanaians in the African Diaspora. On the other hand, newsreaders and reporters in the Ghanaian media are not often publicly taken to task for shortcomings in either pronunciation or usage or structure. Privately, though, the Ghanaian will complain about the inadequate English performance of our TV and FM stations. Whether Sey's (1973, p.7) claim that the Ghanaian aims at perfection and will not "accept anything other than educated British Standard English" is true also today, may be debatable.

\section{English in the School System}

Sutherland-Addy notes: 'We are turning our children into machines to pass exams!' (SutherlandAddy 2011) ${ }^{3}$. Tollefson also observes: 'At a time when English is widely seen as the key to the economic success of nations and economic well-being of individuals, the spread of English also contributes to significant social, political, and economic inequalities'(2000, p. 48). There is a general perception in Ghana of 'falling standards' in English performance, and this is not peculiar to this nation, but the statistics of performance in English at examinations countrywide support this view. The school system is designed to ensure that the young person leaves school fully equipped to participate in the life of modern Ghana, but not all young Ghanaians are able to realise their potential. The Ghanaian education system is highly competitive, as will be shown below - and one can understand that parents are worried that their children will not make it in an educational structure that puts so much emphasis on competence in English.

An urban public Junior High School (JHS) had these results in English at the BECE (Basic Education Certificate Examination) in 2010:

\begin{tabular}{|l|l|l|l|l|l|l|l|l|l|}
\hline $\begin{array}{l}\text { Grade } \\
1\end{array}$ & $\begin{array}{l}\text { Grade } \\
2\end{array}$ & $\begin{array}{l}\text { Grade } \\
3\end{array}$ & $\begin{array}{l}\text { Grade } \\
4\end{array}$ & Grade 5 & $\begin{array}{l}\text { Grade } \\
6\end{array}$ & $\begin{array}{l}\text { Grade } \\
7\end{array}$ & $\begin{array}{l}\text { Grade } \\
8\end{array}$ & Grade 9 & Total \\
\hline 1 & 12 & 13 & 19 & 29 & 4 & 3 & 1 & 0 & 82 \\
\hline
\end{tabular}

In order to get into a good school, a pupil should have no more than an aggregate of 12 - i.e. not more than grade 2 in every subject. So only about $12-13$ pupils out of the 82 from this school would have had a chance of getting into a high school.

The SHS (Senior High School) takes three years of study after completion of the basic school. The students write the West African Senior Secondary School Certificate Examination (WASSCE) after these three years to enable them to enter the university or any other post-secondary institution. The West African Examinations Council grades the exams on a scale of A1- F9. A1 is excellent and represents the highest/ best grade and F9 is fail and represents the lowest grade.

The university accepts results from grades A1-C6 where C6 represents a credit. D7 and E8 are passes but are not accepted for admission to the university. In order to gain entry to a public university, a student would need an aggregate of not more than 16 points accumulated from six subjects which must include at least a credit in English and a credit in Mathematics.

3 Keynote address at the Faculty of Arts Colloquium, University of Ghana, $12^{\text {th }}$ April, 2011.Musings on creativity as the spark for modern nationhood. 
Dako \& Quarcoo / Legon Journal of the Humanities (2017) 20-30

An urban public Senior High School (SSS) had the following results in Core English in 2011:

\begin{tabular}{|l|l|l|l|l|l|l|l|l|l|}
\hline A1 & B2 & B3 & C4 & C5 & C6 & D7 & E8 & F9 & Total \\
\hline 1 & 4 & 99 & 78 & 144 & 216 & 89 & 49 & 11 & 691 \\
\hline
\end{tabular}

As can be seen, the majority of students were within the lower $\mathrm{C}$ range. This means that with the aggregate of 6 subjects required by a candidate to enter university today, any student with a lower grade than B 3 in any subject might not have much of a chance.

In 2009, only $43.90 \%$ of students passed the WASSCE in English. In 2007 the pass grade was as low as 28. $03 \%$ and in 2014, it was $45.2 \%$ (233livenews.com-2014/08/19). The trend shows that performance in English is still below 50\%. Our surveys in Tema, an industrial port city close to the capital Accra, in 2006 and 2010 indicate that urban parents, irrespective of their educational background believe children will perform better academically if they are exposed to only English in school and at home.

\section{Parents' Attitudes to Language}

The educational system in Ghana can be likened to a very broad-based pyramid, where about $20 \%$ get access to a Senior High School and where a fraction of this percentage gets into a university. Parents are aware of the inequality of the education system and invest heavily in their children's education to ensure that they progress from one stage to the next. It is generally thought that English is the main obstacle to academic progression. Consequently, especially in urban areas, English is gradually assuming L1 status as more and more children are sent to English medium schools, and more and more parents choose to speak English in the home. And as life styles and social attitudes are often reflected through language, it becomes difficult to distinguish attitudes to language from attitudes towards social groups (Garret, 2010; Coupland, 2009).

A sample of 100 middle class parents with at least secondary education was interviewed in Tema, to find out how they viewed the role of English in the school and as a language for their children. The findings show that the majority of the parents interviewed were of the opinion that early and exclusive exposure to English promoted higher academic performance in the child (Quarcoo, 2006). In very many higher income homes English has, therefore, become the language used in interaction with the child, and children are sent to English medium schools, so-called 'International Schools'. Interestingly, parents appear not to consider reading an essential teaching tool for language acquisition. A Ghanaian publisher could tell that it is difficult to market children's books in Ghana, but parents are willing to purchase textbooks in a variety of subjects, including English, for their children to use in school and in 'extra classes'.

We asked 20 Senior Members and Senior Staff at the University of Ghana how many books they had bought for their children in the previous year. Five of them had bought what in Ghana is called a 'story book' and eleven had bought set textbooks for their children or grandchildren or relatives' children. Parents, therefore, appear to have more faith in spontaneous language acquisition through speaking and listening than in guided language acquisition through reading - irrespective, it appears, of the competence of the models, be they at home or at school.

Our findings indicate that although most parents believe that their wards will perform better in a monolingual environment, parents also feel coerced into choosing English as the code in the home, because sought-after private schools interview children in English and test their vocabulary before admission. One parent, who had just moved to Ghana from the UK, tells of her daughter's school giving her a list of 200 vocabulary items for the child to learn before being considered for admission to Class One. The parent could see no pedagogical basis for the selection of the items: one of the words was 'carbohydrates'. So in the private schools, children are started off in English already in the nursery school. Because of this early exposure to an English-speaking environment, many parents believe that children from the private schools perform better at the Junior High School level than those from the public schools. This is apparently confirmed because children from private schools get more placements in the prestigious Senior High Schools than their public school counterparts. As a result of 
this, policies have been introduced that give some percentage of placements to children from public schools, especially public schools in the rural areas, in these prestigious Senior High Schools. This is an indication that the English medium school has an advantage over the public school that adheres to the official educational language policy.

In Quarcoo (2006), parents were asked to give at least 3 reasons why they had chosen English over their L1 in communicating with their children. The following are some of the responses in order of importance. These responses were collated as general replies to the question: 'Give three reasons you have for choosing to speak English with your children'. Responses of similar nature were then put together to give the following:

- a) $44 \%$ of the responses stated that selection interviews for admission into nursery schools are conducted in English, and so the three-year old child attending such an interview should be able to speak English to enable it to pass. Where else will a child of three learn English before school apart from the home?

-b) $30 \%$ of the responses stated that it will help the children to be fluent and speak English with confidence.

-c) $28 \%$ of the responses argued that it was the medium of instruction in school and in order not for the children to be handicapped when they go to school, it is better to start them off with English at home.

-d) $26 \%$ stated that since the parents were from different linguistic backgrounds, English served as a common language between them.

-e) $22 \%$ chose it because it would improve their children's living standard in future.

- f) $14 \%$ answered that it was the norm of the day.

- g) $12 \%$ stated that English was an international language, which everyone needed.

- h) $6 \%$ had no particular reason.

- i) $4 \%$ said children who speak English fluently are admired.

Only in response a) can be discerned a critique of the practice. The following two responses give pedagogical reasons why the child should speak English. The excuse of response d) that parents might speak different languages does not sound too convincing - a child can easily acquire two Ghanaian languages. But these responses give the impression that most of the parents interviewed had a positive attitude towards the English language. Their attitude to the local language is not necessarily negative, but it is a competence that is considered of little importance in the child's educational progression, and so the parents are willing to set aside their indigenous languages in favour of English. From talking with the parents, one could only conclude that, so long as the child is in Ghana, it will acquire a local language or two. But the responses also indicate that the parents feel compelled to use English at home because the schools of their choice will admit only children who speak English. And so the importance given to English overrides personal preferences.

Even though we hear dissenting voices from parents, our students at the University of Ghana have obviously not thought too much about this matter. They are, to a large extent, products of English medium schools, so students who were surveyed had a positive attitude towards English because they claimed it is the only language that can push them through the university. Yet the majority of male students at the universities in Ghana hardly ever speak English in informal discourse; their preferred code is Student Pidgin, an acrolectal variety of Ghanaian Pidgin, (Huber, 1999; Dako, 2002, 2013, 2014; Forson, 1996, 2006) ${ }^{4}$. This notwithstanding, more than three quarters of the students responded that English is the most important language for them and also worldwide, when asked how they view it. However, some still felt that their L1 was more important in that it gave them their identity and

4 Student Pidgin (SP) first appeared in the Ghanaian secondary schools in the late 1960s and then moved into the universities. As is the case with Ghanaian Pidgin, SP was from the beginning a male code. We now observe an increasing number of female students adopting this code.

Legon Journal of the Humanities 28.1 (2017) 


\section{Dako \& Quarcoo / Legon Journal of the Humanities (2017) 20-30}

assured them of who they were.

\section{Official Attitudes to Language}

Whereas much lip service is paid to the preservation of culture and tradition in Ghana, little attention is paid to the vehicle of culture: language. A Ghanaian language is not needed for a person to function officially in Ghana. A Ghanaian language is not a requirement for entering either the civil service or the public service, and the constitution does not require a president to speak a Ghanaian language. In fact, the constitution does not state that English is the official language of Ghana, and the Constitution mentions the word 'language' only five times. The first mention is in Article 9:2: 'Except as otherwise provided in article 7 of this Constitution, a person shall not be... registered as a citizen of Ghana unless at the time of his application for registration he is able to speak and understand an indigenous language of Ghana.' The next two references are found in Article 19:2 where it is stated 'A person who is arrested....shall d) be informed immediately in a language that he understands...and in h) be permitted to have, without payment by him, the assistance of an interpreter where he cannot understand the language used at the trial.' Then again in Article 26.1 it is stated 'Every person is entitled to enjoy, practise, profess, maintain and promote any culture, language, tradition or religion subject to the provisions of this Constitution' and in Article 39:3 we read 'The State shall foster the development of Ghanaian languages and pride in Ghanaian culture [emphasis added].

From the above, we can conclude that language does not feature prominently in the Ghanaian agenda and discourse.

\section{English in the Public Domain}

English is the main language for all official duties in Ghana. English is therefore expected to be used in all public domains. We tried to ascertain whether this is what actually pertains. A random survey undertaken in 2010 in the Accra-Tema metropolitan area shows that though English is the official language, it is mainly used at formal meetings, when an official visits or when deference is shown towards a superior or a customer. The languages observed used in public offices in the AccraTema area are mainly Twi and Ga. To gather our data we asked the managers of four different banks, Ghana Telecom, the Internal Revenue office in Tema, offices of the Tema Development Corporation, two insurance companies and the offices of Urban Roads, whether we could make a survey on language attitudes and practices among their staff. We had unexpected cooperation, and 400 questionnaires in all were distributed to the managers of the various establishments who then distributed them to their staff. ${ }^{5}$ We got 120 questionnaires back. $76 \%$ of the respondents claimed they speak only English at work. Meanwhile the area manager in one of the banks in Tema actually gave instructions to the secretary in Ga in the presence of the researcher after he had told her that he uses only English. The secretary subsequently spoke Ewe to another colleague and Twi to the researcher. In three other public offices in Tema, Twi and Ga were the only languages used with all the clients that came to transact business, except in the few cases when the customer initiated the discourse in English and thus compelled the officials to respond likewise.

The workers also claimed they use more English with their superiors than any other language. Out of the 120 respondents, 98 (84\%) said they use only English with their boss or senior. Only 6 $(5.2 \%)$ said that they use an indigenous language, and 12(10.3\%) said they use both English and an indigenous language ${ }^{6}$ Twi seems to be the indigenous language most frequently used when the boss or a senior colleague is addressed.

$62(54.9 \%)$ employees claimed they spoke only English with colleagues. This appeared not to be the case, however, for when the researcher placed herself on a chair in some of the offices to listen to what actually took place, the results indicated that Twi and sometimes Ga were the languages mostly used. $27(23 \%)$ said they used both English and an indigenous language, and $24(21.2 \%)$ said they used an indigenous language only. Again, Twi seemed to be the language most commonly used. It was

Using the SPSS statistical package for the Social Sciences

Some code switching was observed, but in most cases language alternation was noted. 
noted that some male employees spoke SP (student pidgin) to male colleagues. But speaking Twi or $\mathrm{Ga}$, etc. actually meant 'codeswitching', for the local languages were frequently interspersed with English items.

When asked whether English should replace the local languages in Ghana, 97 (89\%) said no, indicating that Ghanaians still want their languages, yet when asked whether an indigenous language should be made a national language, $68(59.1 \%)$ said no, and only 47(40.5\%) said yes. This corresponds to Guerini's (2008) findings. .

In an interview with some of the employees who were asked why they use an indigenous language instead of English, some said that it makes communication with those who cannot speak English easier and also does not intimidate customers. Some also said they did not see why they should speak English with someone who can speak their language.

These responses are somehow baffling because these same people claim they speak only English to their children (83 responses representing 91\%) because they want them to be competent in that language, yet they themselves do not see why they should speak English with someone who can speak their local language. There might be a conflict of identity here. The parent raising a child to conform to the perceived values of a desired English speaking social class, adopts a different identity from that assumed by the same person as a wage earner in a public office surrounded by Ghanaian colleagues of a similar background and with the same level of education. Yet we can also argue that English is a Ghanaian language that has carved distinct domains for itself in the urban setting and that one of the domains of English is the middle class home with its television, computer, video games and CD player. And so the responses from the questionnaire indicate that English is a valued language used mostly in formal situations whereas the indigenous languages are used in other domains. But the responses also show that though many Ghanaians do not want an indigenous language as a national language, they still want to maintain their ethnic language. Ghanaians clearly have a positive attitude towards English, but their attitude towards the indigenous languages is not so clear.

\section{Discussion}

The UNESCO declaration on the use of the vernacular in education states: "It is axiomatic that the best medium for teaching a child is his mother tongue" (UNESCO, 1953, p. 11) and in 2003 it reiterates that it is thus urgent to take action to encourage broad and international commitment to promoting multilingualism and linguistic diversity, including the safeguarding of endangered languages.

Recent evidence from research done in rural districts of Ghana (Ameka, 2009; Brew-Daniels, 2010), in which teacher trainees who teach in English under supervision in the higher classes of Primary School and Junior High School are recorded, reveals that the teacher in training has an inadequate grasp of English at all levels of performance and can therefore not be a desirable model in the English-speaking classroom. Extensive code switching is therefore the norm. In a situation where teachers do not have the vocabulary in their L1 to teach adequately and also lack the English resources they would need to deliver adequate lessons in the classroom, codeswitching seems to be the obvious language strategy. English-Twi codeswitching is also the language mode of the study groups monitored at one of our universities (Quarcoo, 2013).

The English Medium School encourages the dilution of local language education and the knowledge, learning and teaching of local culture. And as local languages are denigrated and marginalised, the values of the urban middle class come to dominate the cultural debate in the country. It is the children of the urban middle class, products of the English Medium Schools, who dominate the University intake. This demonstrates that while English opens the door to higher education to a few, it at the same time bars access to higher education for the majority.

It is the creation of this minority elite, whose strategy of symbolic dominations is what MyersScotton (1993b) calls 'elite closure', that is compelling many Ghanaians to choose English over their L1. Even though Ghanaians have great respect for English and are prepared to choose it over their L1 in speaking to their children, it is still seen as a foreign language by many. There have been voices 


\section{Dako \& Quarcoo / Legon Journal of the Humanities (2017) 20-30}

who are concerned about the exclusion of the local languages in favour of English. Some have even decried the insertion of English words into the indigenous languages through either borrowing or code switching. An editorial in a national daily reported that "Ghanaians seem to be losing the ability to communicate fluently in their mother tongues, their own Ghanaian languages." (Ghanaian Times, July $10,2008$ p. 2$)^{7}$. The same editorial singled out Akan as the worst culprit: "Akan speakers are especially guilty of what one can term the 'Akanglish' phenomenon' - or what others call 'Twinglish' i.e. extensive code switching. ${ }^{8}$ This could suggest that Ghanaians have a love-hate relationship with English. On the one hand it is necessary to have it since it puts the English speakers in a position of authority and enhances their social and economic power. On the other hand, it is a usurper which threatens the Ghanaianness of the Ghanaian.

\section{Concluding Remarks}

We have tried to look at Ghanaian attitudes towards English in relation to the indigenous languages. The work has shown that English is a high language in some domains in Ghana (Ferguson, 1953; Fishman, 1967), firstly because it is the de facto official language and is therefore used for official duties, in parliament, in the judiciary, in the media etc. and because it is the main language of education. Secondly, the language policies on education are skewed towards the use of English. Again, these policies are enforced in the public schools whereas the private schools are allowed to interpret the Ghana Education Policy to suit their individual attitude to local language education, thus giving children from private schools some advantage over those from the public schools.

Our findings further show that Ghanaians have a positive attitude towards English because it is the sole language that can enhance their chances of moving up the educational ladder and thus ensuring that they get secure and well-paid jobs. Our findings have also shown that although English is a highly regarded language, Ghanaians still want to keep their indigenous languages, but that they subconsciously refuse to transmit these languages to their children by speaking English to them at home. Parents appear to have the misconception that the children will easily pick up a local language so long as they live in Ghana. They appear not to consider that if a child has English at home, in school, in church, and among friends, it will not get any opportunity to learn the indigenous language and so will not know it at all. 


\section{References}

Adjaye, S. A. (2005). Ghanaian English pronunciation. New York, NY: The Edwin Mellen Press Ltd. Alexander, N. (2009). Evolving African approaches to the management of linguistics diversity: The Acalan project. Language Matters, 40 (2), 117-132.

Ameka, C. K. (2009). Codeswitching as a medium of instruction in selected schools in the Volta Region (MPhil thesis). University of Ghana, Legon.

Anderson, J. A. (2009). Codifying Ghanaian English: Problems and prospects. In T. Hoffman \& L. Siebers (Eds.), Problems, properties and prospects World Englishes (19-36).Amsterdam, Netherlands: John Benjamins.

Andoh-Kumi, K. (1997). Language education policies in Ghana. Accra, Ghana: Crigle.

Anyidoho, A. \& Kropp-Dakubu M. E. (2008). Language, nationalism and national identity in Ghana. In A. Simpson (Ed.), Language and national identity in Africa (pp. 141-157). Oxford, UK: Oxford University Press.

Arthur-Shoba, J., Dako, K., \& Quartey, E. (2013). Locally acquired foreign accent (LAFA) in contemporary Ghana. World Englishes, 32(2), 230-242.Amsterdam, Netherlands: John Benjamins.

Baker, C. \& Prys-Jones, S. (1998).Encyclopaedia of bilingualism and bilingual matters. Multilingual Matters. Clevedon, UK: Multilingual Matters Ltd.

Bamgbose, A. (1995). Comment by Ayo Bamgbose. In E.A. Afendras (Ed.)on 'new/nonnative Englishes: A gamelan'. Journal of Pragmatics 24, 295-321.

Brew-Daniels, J. (2010). Twi-English codeswitching in the classroom: A case study of some selected colleges of education in the Ashanti Region (MPhil thesis). University of Ghana, Legon.

Bruku, B. O. (2010).A sociolinguistic analysis of LAFA: A locally acquired foreign (American) English accent in Ghana (MPhil thesis). University of Ghana, Legon.

Chimbutane, F. (2011). Rethinking bilingual education in postcolonial contexts. Multilingual Matters (pp.1-12).Bristol,UK: Buffalo.

Coupland, N. (2009). Dialects, standards and social change. In M. Maagaard. F. Gregerson, P. Quist \& J. N. Jørgensen (Eds.), Language attitudes, $\quad$ standardisation and language change (pp. 2749). Oslo, Norway: Novus.

Dako, K. (2011). The sociolinguistic situation of non-native lingua francas in Ghana: English, Hausa and Pidgin. In H. Lauer \& K. Anyidoho, (Eds.), Reclaiming the human sciences and humanities through African perspectives(pp. 1474-1484). Accra, Ghana: Sub Saharan Publishers.

Dako, K. (2003a). The sound system of Ghanaian English. Exploration, 1 (1),107-119.

Dako, K. (2003b). Ghanaianisms: A glossary, Accra: Ghana Universities Press.

Dako, K. (2002). Student pidgin (SP): The language of the educated male elite. IAS Research Review, NS, 18 (2), 53-62.

Dako, K. (2001). Ghanaianisms: towards a semantic and a formal classification. English World Wide, 22 (1), 23-54.

Dako, K. (1991). Some reflections on English in Ghana: Terminology and classification. Proceedings of the Ghana English Studies Association Conference, 1, 42-45. Legon: University of Ghana, Daily Guide (2011, March 29).

Forson, B. E. (1996) An investigation into the argot (pidgin) as a means of communication among students in Ghanaian secondary schools (MPhil Thesis). University of Ghana, Legon.

Forson, B. E. (2006) Student Pidgin English (SPE): A neo-Ghanaian English in vitro. (Doctoral thesis). University of Ghana, Legon.

García, O. (2007). Bilingual education in the $21^{\text {st }}$ century. Oxford, UK: Wiley- Blackwell.

Garret, P. (2010). Attitudes to language. Cambridge, UK: Cambridge University Press.

Ghanaian Times (2008, July 10), Dealing with the 'Akan English' phenomenon. Editorial.

Guerini, F. (2007). Multilingualism and language attitudes in Ghana: Apreliminary survey. Ethnorêma, Anno IV, 4, 1-33. http://www.ethnorema.it

Huber, M. \& DakoK. (2008). Ghanaian English: Morphology and syntax. In B. Kortmann 
\& E. Schneider (Eds.),Varieties of English (Vol 4,pp. 368 - 394). Berlin, Germany: De Gruyter.

Huber, M. (2008). Ghanaian English: Phonology. In B. Kortmann, \& E. Schneider (Eds.), Varieties of English (Vol. 4, pp. 67-101). Berlin, Germany:De Gruyter.

Kiessling, R. \& Maarten M. (2004). Urban youth languages in Africa. Anthropological Linguistics, 46 (3), 303-341.

Koranteng, L. (2006). Ghanaian English: A description of its sound system and phonological features (Doctoral thesis). University of Ghana, Legon.

Mc Laughlin, F. (2009). Introduction to the languages of urban Africa. In F. Mc Laughlin (Ed.), The Languages of Urban Africa. (pp. 1-18).Oxford, UK: Bloomsbury Publishers.

Myers-Scotton, C. (1993b). Elite closure as a powerful language strategy: The African case. International Journal of the Sociology of Language, 103, 149-63.

Mufweme, S. S. (2010). Globalization and the spread of English: What does it mean to be Anglophone? English Today, 101 (26), 57-59.

Platt, J., Weber, H. \& Ho, M.L. (1984). The New Englishes. London, UK: RKP.

Quarcoo, M. (2006). English as L1: The reasons why some parents use English with their children: A study of Tema Community 11 (Long Essay). University of Ghana, Legon.

Quarcoo, M. (2013) Codeswitching in academic discussions: A discourse strategy by students in the University of Education, Winneba(Doctoral thesis). University of Ghana, Legon.

Saah, K. K. (1986). Language use and attitudes in Ghana. Anthropological Linguistics, 28 (3), 367378.

Schneider, E. W. (2003). The dynamics of New Englishes: From identity construction to dialect birth. Language,79 (2), 233-281.

Sey, K.A. (1973). Ghanaian English. London, UK: Macmillan.

The Statesman (2002, July 10).New language policy for primary and basic education.

Tollefson, J. W. (2000). Language ideology and language education. In J. Shaw, D. Lubelska, \& M. Noullet (Eds.), Partnership and interaction: Proceedings of the Fourth International Conference on Language and Development (pp. 43-52). Bangkok, Thailand: Asian Institute of Technology.

Yankson, S. A. (2009). Sociolinguistic aspects of Akan in Accra. IAS Research Review, 25 (2), 83101. 